\title{
Spatial Visualization by Orthogonal Rotations
}

\author{
Jianping Yue \\ Essex County College
}

\begin{abstract}
Spatial visualization skills are important in engineering graphics and computer-aided design courses, especially in three-dimensional solid modeling that has been widely adopted in college curricula and applied in industries. Researchers have developed various types of tests to assess students' spatial visualization abilities. Orthogonal rotation about the axes of the Cartesian coordinate system is one of the most commonly used testing methods for spatial visualization. In this paper, the author first presents the maximum possible number of orthogonal rotational views of an object. Analyses are presented for two spatial visualization tests by their representations of the possible orthogonal rotations and the difficulty of visualization. Finally, the author makes some suggestions on the improvements of spatial visualization tests based on the possible orthogonal rotations.
\end{abstract}

\section{Introduction}

Spatial visualization skills have been considered important in engineering graphics. In the 1980's, computer-aided design (CAD) was introduced into classrooms, along with the development of computer hardware and software. Nowadays, three-dimensional (3D) solid modeling CAD is very popular in industrial applications and a fundamental skill for engineering and technology students. These developments have revitalized educators' interest in spatial visualization $^{1,2}$.

Spatial visualization skills may be tested by various formats ${ }^{3,4}$, such as surface folding/unfolding, symmetry, revolution, projection, section, and rotation. Among these formats, rotation of a $3 \mathrm{D}$ object about one or more axes is a popular method.

Psychologists have studied spatial visualization from the perspective of cognition and perception. Shepard and Metzler ${ }^{5}$ designed an experiment to investigate the reaction time of visualizing rotated 3D objects. The objects were composed of ten face-to-face connected cubes with three right-angled bends and two free ends, and distinct by the number of cubes in the sections and the orientation of the bends. The rotations were from $0^{\circ}$ to $180^{\circ}$ with $20^{\circ}$ increments either in the projection plane or in depth. Vandenberg and Kuse ${ }^{6}$ later developed a test based on Shepard and Metzler's model, which is known as the mental rotation test (MRT) and widely used. Because engineering and technical graphics involve multiview or orthogonal projections, the rotational 
spatial visualization tests for engineering students usually took the form of isometric views and orthogonal rotations. Guay ${ }^{7}$ developed the Purdue Spatial Visualization Test - Visualization of Rotations (PSVT-R), which made orthogonal rotations of 3D objects about the axes of the Cartesian coordinate system. Sorby ${ }^{4}$ recently released a workbook on several types of spatial visualization, including orthogonal rotations.

Yue ${ }^{8}$ categorized the 30 problems of orthogonal rotations in the PSVT-R test into four types or levels of difficulty of rotations based on the degree of rotations and the axes involved. For a sample of 64 freshman and sophomore students in engineering graphics and CAD classes, he found that the mean score differences were significant only for $\mathrm{X}_{1}-\mathrm{X}_{2}$ and $\mathrm{X}_{1}-\mathrm{X}_{4}$, where $\mathrm{X}_{\mathrm{i}}$ is the mean score for the rotation type $\mathrm{i}$ with 1 the simplest and 4 the most difficult, and there were no significant differences for all other four pairs. This finding raised several questions about the design of spatial visualization tests with orthogonal rotations. How many views of orthogonal rotations are there? What kinds of orthogonal rotations do exist? In order to subjectively measure the abilities and skills of spatial visualization, how can we design tests that are based on the limits and patterns of orthogonal rotations if there are any? This paper will discuss these questions.

\section{Orthogonal Rotations}

\subsection{Definition and notations}

Orthogonal rotations are the right angle $\left( \pm 90^{\circ}\right)$ and its multiple $\left( \pm \mathrm{n} 90^{\circ}, \mathrm{n}=1,2,3, \ldots\right)$ rotations of a $3 \mathrm{D}$ object about the axes of the Cartesian coordinate system. Orthogonal rotations may be denoted by:

$$
\pm \mathrm{nx}_{\mathrm{i}} ; \mathrm{i}=1,2 \text {, or } 3 ; \mathrm{n}=1,2,3, \ldots
$$

Where $\mathrm{x}_{\mathrm{i}}$ are the three axes of the Cartesian coordinate system, i.e., $\mathrm{x}_{1}=\mathrm{x}, \mathrm{x}_{2}=\mathrm{y}$, and $\mathrm{x}_{3}=\mathrm{z} . \mathrm{n}$ is the number of orthogonal $\left( \pm 90^{\circ}\right)$ rotations. The sign or direction of rotation follows righthand rule, i.e., $+/$ - for $\mathrm{CCW} / \mathrm{CW}$. For example, $3 \mathrm{x}$ is a $270^{\circ} \mathrm{CCW}$ rotation about the $\mathrm{x}$-axis. If subsequent rotations occur about other axes, the sequence or step is denoted by an arrow ( $)$ symbol or space when there is no confusion. For example, $-\mathrm{x}-2 \mathrm{y}$ or $-\mathrm{x} 2 \mathrm{y}$ means it first rotates $90^{\circ} \mathrm{CW}$ about the $\mathrm{x}$-axis and then rotates $180^{\circ} \mathrm{CCW}$ about the $\mathrm{y}$-axis.

\subsection{Total number of views by orthogonal rotations}

Axonometric views or projections are usually adopted in spatial visualization tests ${ }^{4-7}$. In axonometric projections, only three surfaces of a rectangular block have explicit views at a time, and there is only one vertex that is common to these three surfaces. Among the three types of axonometric projection of isometric, diametric, and trimetric, isometric projection is the most popular one due to its simplicity.

Proceedings of the 2004 American Society for Engineering Education Annual Conference \& Exposition Copyright $(\mathrm{C} 2004$, American Society for Engineering Education 
Theorem 1: There are a total number of 24 axonometric views of an object at a projection angle.

Proof: Each object can be enclosed inside a rectangular box with 8 vertices. Since there are only 3 unique axonometric views for each vertex at a projection angle (Figure 1), then there are a total number of $24(8 \times 3)$ axonometric views. The uniqueness is in the sense of orientation. For example, the 3 projections in Figure 1 have the same unhidden surfaces, but with different orientations, there are, therefore, 3 unique views.

Corollary 1.1: There are a total number of 24 isometric views of an object.

Since isometric projection is a special case of axonometric projections, in which all 3 dimensions have equal angles with the projection plane, it follows from Theorem 1 that there are a total number of 24 isometric views.
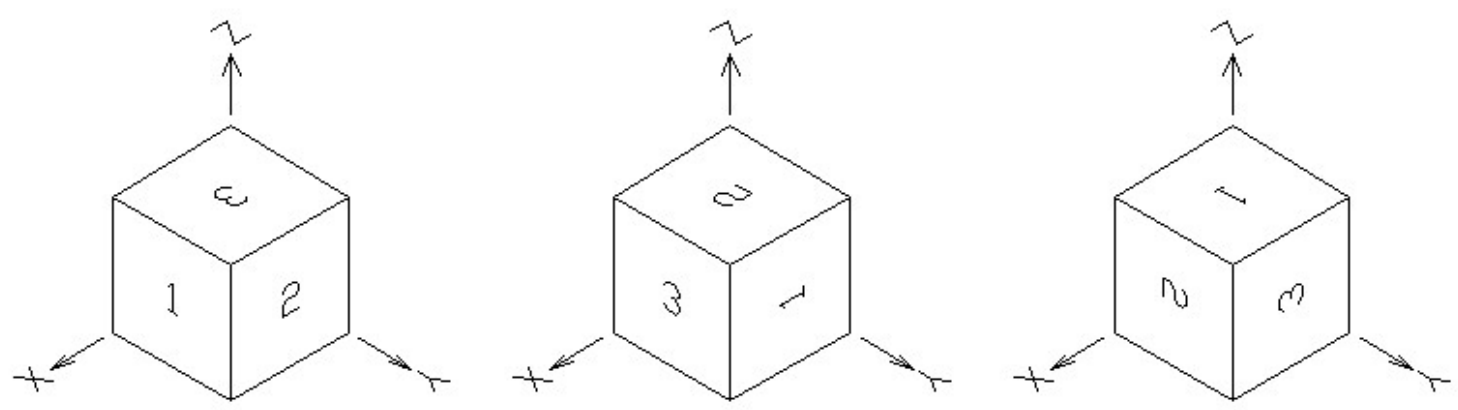

Figure 1. Three unique views for each vertex

All 24 possible isometric views are shown in Figure 2. In the figure, each view is named by a letter with a number subscript. The letter indicates a rotated surface $(\mathrm{T}=\mathrm{Top}, \mathrm{B}=\mathrm{Bottom}, \mathrm{F}=$ Front, $\mathrm{R}=$ Rear, $\mathrm{L}=\mathrm{Left}$ side, and $\mathrm{S}=$ right Side). The number subscript indicates the number of orthogonal rotations about the axis along the surface vector of that surface $\left(0=0^{\circ}, 1\right.$ is $90^{\circ}, 2$ is $2 \times 90^{\circ}=180^{\circ}$, and 3 is $3 \times 90^{\circ}=270^{\circ}$ ). For example, $B_{1}$ represents the view that is produced by first rotating a marked surface (the top surface is chosen as the marked surface in the initial view $\left.\mathrm{T}_{0}\right)$ into the bottom surface $\left(\mathrm{B}_{0}\right)$ and then rotating $90^{\circ}$ about the $\mathrm{z}$-axis, and vice versa. 

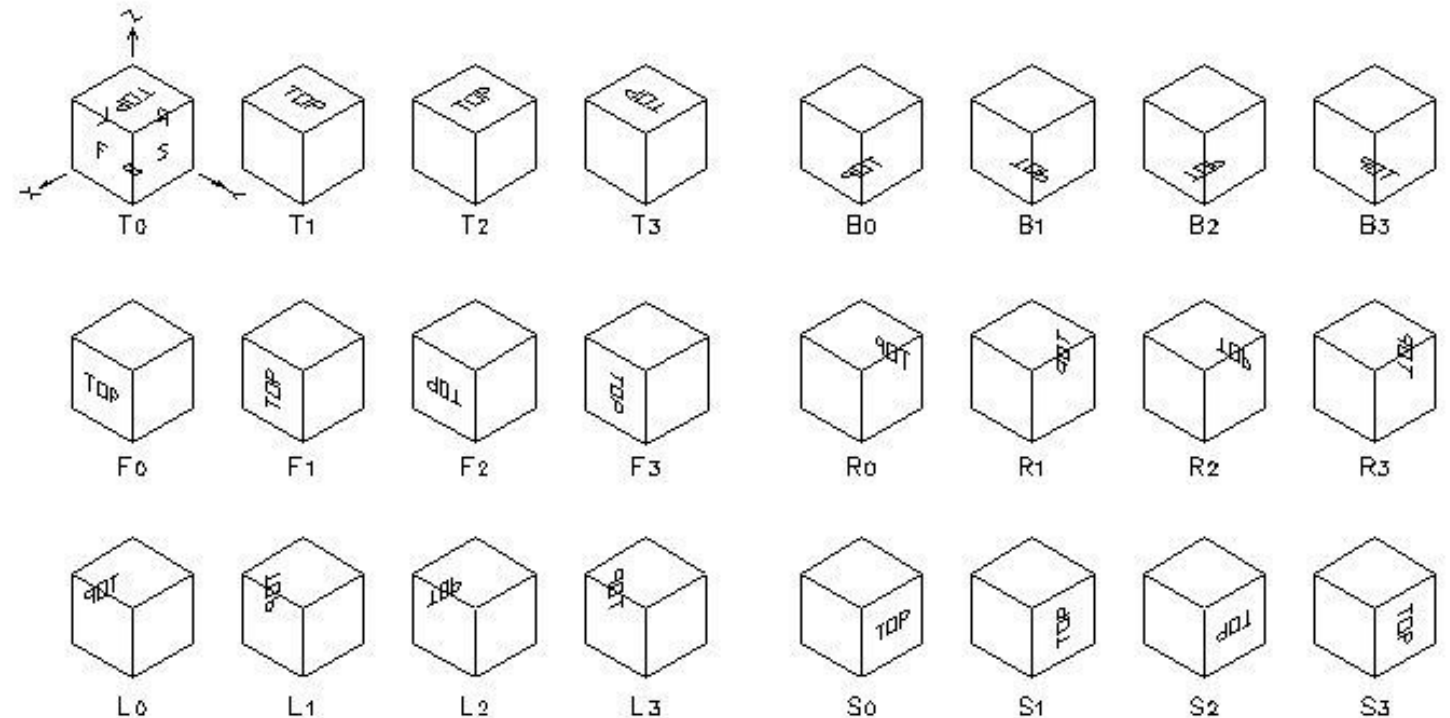

Figure 2. All 24 possible isometric views

\subsection{Number of orthogonal rotations}

Theorem 2: There are an unlimited number of orthogonal rotations that result in the same view.

Proof: a) There are only four unique orientations $\left(0^{\circ}, 90^{\circ}, 180^{\circ}\right.$, and $\left.270^{\circ}\right)$ by orthogonally rotating an object about an axis. But, any of these four orientations can be represented by an unlimited number of rotations that are multiples of a full circle of rotation $\left(360^{\circ}\right)$ in either direction. In other words, there are unlimited rotations of $360^{\circ}$ and its multiples about an axis, which result in the same view:

$$
\pm 4 \mathrm{nx}_{\mathrm{i}} ; \mathrm{i}=1,2 \text {, or } 3 ; \mathrm{n}=1,2,3, \ldots
$$

b) For orthogonal rotations about multiple axes, there are additional variations of combination and permutation of the rotating sequence to result in the same view. For example, the same view will be generated after the following unlimited number of rotations:

$$
\pm 2 \mathrm{nx}_{\mathrm{i}} \triangleright 2 \mathrm{nx}_{\mathrm{j}} \triangleright 2 \mathrm{nx}_{\mathrm{k}} ; \mathrm{n}=1,2,3, \ldots ; \mathrm{i}, \mathrm{j}, \& \mathrm{k}=1,2,3 ; \mathrm{i} \neq \mathrm{j} \neq \mathrm{k}
$$




\section{Degree of Difficulties of Visualization}

The degree of difficulties of spatial visualization by orthogonal rotations depends on several factors. They include the number of axes involved, the degree of rotations, and the direction of rotation. In a Cartesian coordinate system, an object may rotate about the $\mathrm{x}, \mathrm{y}$, and $\mathrm{z}$-axes. It is obvious that the more axes to rotate about, the harder to visualize. Orthogonal rotations about an axis are in the increment of 90 degrees, i.e., $90^{\circ}, 180^{\circ}$, and $270^{\circ}$ (or $-270^{\circ},-180^{\circ}$, and $-90^{\circ}$ respectively). A full circle rotation of $360^{\circ}$ simply returns to the original view. Finally, an object may rotate counterclockwise/clockwise (CCW/CW or +/-) about an axis. Among these factors, the direction of rotation seems to have the least significance. For example, the positive and negative $90^{\circ}$ rotations about an axis are analogous to left and right hands, and both may be equally easy to visualize. Shepard and Metzler's ${ }^{5}$ experiment indeed showed that the reaction time of visualizing a rotated $3 \mathrm{D}$ object increased linearly with the angle of rotation (from $0^{\circ}$ to $180^{\circ}$ with $20^{\circ}$ increments), but was not affected by the different orientations of rotation (rotation in the projection plane or in depth). Therefore, the orthogonal rotations with the only difference of the directions of rotation $(\mathrm{CW} / \mathrm{CCW})$ may be considered as having the same degree of difficulty in the design of visualization tests.

As shown in Figure 2, the rotations about each axis create nine individual views (Table 1). The rotations, which first rotate $90^{\circ}$ about one axis and then rotate $90^{\circ}$ about another axis, produce eight additional views (Table 2). Finally, the rotations of a $90^{\circ}$ about one axis followed by a $180^{\circ}$ about another axis generate the remaining six independent views (Table 3 ).

Table 1. Views from the rotations about one axis $\left(\mathrm{x}_{\mathrm{i}}\right)$

\begin{tabular}{|c|c|c|c|}
\hline Axis $\backslash$ Angle & $90^{\circ}\left(-270^{\circ}\right)$ & $180^{\circ}\left(-180^{\circ}\right)$ & $270^{\circ}\left(-90^{\circ}\right)$ \\
\hline $\mathrm{X}$ & $\mathrm{L}_{0}$ & $\mathrm{~B}_{0}$ & $\mathrm{~S}_{2}$ \\
\hline $\mathrm{Y}$ & $\mathrm{F}_{3}$ & $\mathrm{~B}_{2}$ & $\mathrm{R}_{3}$ \\
\hline $\mathrm{Z}$ & $\mathrm{T}_{1}$ & $\mathrm{~T}_{2}$ & $\mathrm{~T}_{3}$ \\
\hline
\end{tabular}

Table 2. Views from the rotations about two axes $\left( \pm \mathrm{x}_{\mathrm{i}} \pm \mathrm{x}_{\mathrm{j}}\right)$

\begin{tabular}{|c|c|c|c|}
\hline $1^{\text {st }} 90^{\circ}$ rotation $\backslash 2^{\text {nd }} 90^{\circ}$ rotation & $\pm \mathrm{X}$ & $\pm \mathrm{Y}$ & $\pm \mathrm{Z}$ \\
\hline \multirow{4}{*}{$\pm \mathrm{X}$} & $\left(++\mathrm{B}_{0}\right)$ & $++\mathrm{L}_{1}$ & $++\mathrm{F}_{0}$ \\
& $\left(+-\mathrm{T}_{0}\right)$ & $+-\mathrm{L}_{3}$ & $+-\mathrm{R}_{0}$ \\
& $\left(-+\mathrm{T}_{0}\right)$ & $-+\mathrm{S}_{3}$ & $-+\mathrm{R}_{2}$ \\
& $\left(--\mathrm{B}_{0}\right)$ & $--\mathrm{S}_{1}$ & $--\mathrm{F}_{2}$ \\
\hline & $++\mathrm{F}_{0}$ & $\left(++\mathrm{B}_{2}\right)$ & $++\mathrm{S}_{3}$ \\
& $+-\mathrm{F}_{2}$ & $\left(+-\mathrm{T}_{0}\right)$ & $+-\mathrm{L}_{1}$ \\
& $-+\mathrm{R}_{0}$ & $\left(-+\mathrm{T}_{0}\right)$ & $-+\mathrm{L}_{3}$ \\
& $--\mathrm{R}_{2}$ & $\left(--\mathrm{B}_{2}\right)$ & $--\mathrm{S}_{1}$ \\
\hline & $++\mathrm{L}_{3}$ & $++\mathrm{F}_{0}$ & $\left(++\mathrm{T}_{2}\right)$ \\
& $+-\mathrm{S}_{3}$ & $+-\mathrm{R}_{2}$ & $\left(+-\mathrm{T}_{0}\right)$ \\
& $-+\mathrm{L}_{1}$ & $-+\mathrm{F}_{2}$ & $\left(-+\mathrm{T}_{0}\right)$ \\
& $--\mathrm{S}_{1}$ & $--\mathrm{R}_{0}$ & $\left(--\mathrm{T}_{2}\right)$ \\
\hline
\end{tabular}

Proceedings of the 2004 American Society for Engineering Education Annual Conference \& Exposition Copyright (C) 2004, American Society for Engineering Education 
Table 3. Views from the rotations about two axes $\left( \pm \mathrm{x}_{\mathrm{i}} \pm 2 \mathrm{x}_{\mathrm{j}}\right)$

\begin{tabular}{|c|c|c|c|}
\hline $1^{\text {st }} 90^{\circ}$ rotation $\backslash 2^{\text {nd }} 180^{\circ}$ rotation & $\pm 2 \mathrm{X}$ & $\pm 2 \mathrm{Y}$ & $\pm 2 \mathrm{Z}$ \\
\hline & $\left(++\mathrm{S}_{2}\right)$ & $++\mathrm{L}_{2}$ & $++\mathrm{S}_{0}$ \\
& $\left(+-\mathrm{S}_{2}\right)$ & $+-\mathrm{L}_{2}$ & $+-\mathrm{S}_{0}$ \\
& $\left(-+\mathrm{L}_{0}\right)$ & $-+\mathrm{S}_{0}$ & $-+\mathrm{L}_{2}$ \\
& $\left(--\mathrm{L}_{0}\right)$ & $--\mathrm{S}_{0}$ & $--\mathrm{L}_{2}$ \\
\hline \multirow{4}{*}{$\pm \mathrm{Y}$} & $++\mathrm{F}_{1}$ & $\left(++\mathrm{R}_{3}\right)$ & $++\mathrm{R}_{1}$ \\
& $+-\mathrm{F}_{1}$ & $\left(+-\mathrm{R}_{3}\right)$ & $+-\mathrm{R}_{1}$ \\
& $-+\mathrm{R}_{1}$ & $\left(-+\mathrm{F}_{3}\right)$ & $-+\mathrm{F}_{1}$ \\
& $--\mathrm{R}_{1}$ & $\left(--\mathrm{F}_{3}\right)$ & $--\mathrm{F}_{1}$ \\
\hline & $++\mathrm{B}_{3}$ & $++\mathrm{B}_{1}$ & $\left(++\mathrm{T}_{3}\right)$ \\
$\pm \mathrm{Z}$ & $+-\mathrm{B}_{3}$ & $+-\mathrm{B}_{1}$ & $\left(+-\mathrm{T}_{3}\right)$ \\
& $-+\mathrm{B}_{1}$ & $-+\mathrm{B}_{3}$ & $\left(-+\mathrm{T}_{1}\right)$ \\
& $--\mathrm{B}_{1}$ & $--\mathrm{B}_{3}$ & $\left(--\mathrm{T}_{1}\right)$ \\
\hline
\end{tabular}

The rotations in Tables 1 through Table 3 include all 24 possible views. Further rotations merely reproduce the same set of views and thus are not necessary. The two signs in front of the notation of the views are the directions of the first and second rotations. The parentheses indicate repetitions of the rotations about a single axis, and the initial view. For example, the views in the parentheses in Table 2 represent two consecutive $90^{\circ}$ rotations about the same axis either in the same direction or opposite directions. The two $90^{\circ}$ rotations in the same direction are the same as a $180^{\circ}$ rotation about one axis as listed in Table 1, while those in the opposite directions are equivalent to no rotation at all and remain as the original view. Other repeated views generated by different sequences and directions of rotation are also included in Table 2 and Table 3. A summary of these orthogonal rotations according to their degrees of difficulty is listed in Table 4.

Table 4. Summary of orthogonal rotations

\begin{tabular}{|l|l|l|l|c|}
\hline \multicolumn{1}{|c|}{ Type of Rotations } & $\begin{array}{c}\text { Rotations } \\
\text { about Axes }\end{array}$ & \multicolumn{1}{|c|}{$\begin{array}{c}\text { Degrees of } \\
\text { Rotations }\end{array}$} & \multicolumn{1}{|c|}{ Independent Views } & $\begin{array}{c}\text { Number } \\
\text { of Views }\end{array}$ \\
\hline Type 0: Initial view & & $0^{\circ}$ & $\mathrm{T}_{0}$ & 1 \\
\hline Type I: $90^{\circ}$ one axis & $\pm \mathrm{x}_{\mathrm{i}}$ & $\pm 90^{\circ}$ & $\mathrm{F}_{3}, \mathrm{~L}_{0}, \mathrm{R}_{3}, \mathrm{~S}_{2}, \mathrm{~T}_{1}, \mathrm{~T}_{3}$ & 6 \\
\hline Type II: $180^{\circ}$ one axis & $\pm 2 \mathrm{x}_{\mathrm{i}}$ & $\pm 180^{\circ}$ & $\mathrm{B}_{0}, \mathrm{~B}_{2}, \mathrm{~T}_{2}$ & 3 \\
\hline Type III: $90^{\circ}$ one axis $90^{\circ}$ another axis & $\pm \mathrm{x}_{\mathrm{i}} \pm \mathrm{x}_{\mathrm{j}}$ & $\pm 90^{\circ}- \pm 90^{\circ}$ & $\mathrm{F}_{0}, \mathrm{~F}_{2}, \mathrm{~L}_{1}, \mathrm{~L}_{3}, \mathrm{R}_{0}, \mathrm{R}_{2}, \mathrm{~S}_{1}, \mathrm{~S}_{3}$ & 8 \\
\hline Type IV: $90^{\circ}$ one axis $180^{\circ}$ another axis & $\pm \mathrm{x}_{\mathrm{i}} \pm 2 \mathrm{x}_{\mathrm{j}}$ & $\pm 90^{\circ}- \pm 180^{\circ}$ & $\mathrm{B}_{1}, \mathrm{~B}_{3}, \mathrm{~F}_{1}, \mathrm{~L}_{2}, \mathrm{R}_{1}, \mathrm{~S}_{0}$ & 6 \\
\hline
\end{tabular}

Several characteristics are associated with orthogonal rotations. (1) In general, rotations about an axis with conterminal angles generate the same view. Some examples of orthogonal rotations are: (a) Half circle rotations about an axis in either direction always generate the same view, i.e., 
$180^{\circ}=-180^{\circ}$ or $2 \mathrm{x}_{\mathrm{i}}=-2 \mathrm{x}_{\mathrm{i}}$; (b) A $90^{\circ}$ rotation in one direction and a $270^{\circ}$ rotation in another direction about an axis, as well as their multiples, always generate the same view, i.e., $270^{\circ}=$ $90^{\circ}$ and $-270^{\circ}=90^{\circ}$, or $\pm \mathrm{x}_{\mathrm{i}}=\mp 3 \mathrm{x}_{\mathrm{i}}$; (c) Full circle rotations, as well as their multiples, in either direction about an axis always return to the initial view, i.e., $\pm \mathrm{n} 360^{\circ}$ or $\pm 4 \mathrm{nx}_{\mathrm{i}}$ merely reproduce $^{\circ}$ the same view. Therefore, full circle rotations can be added to any rotation without changing the view, i.e., $2 x_{i} \pm 4 n x_{i}=-2 x_{i} \pm 4 n x_{i}, \pm x_{i} \pm 4 n x_{i}=\mp 3 x_{i} \pm 4 n x_{i}$, etc. (2) The same view can be generated by more than one sequence of rotations. Some examples include: $x z, y x$, and zy all generate the same view (F0 in Table 2) and $\pm x_{i} \pm 2 x_{j}=\mp x_{i} \pm 2 x_{k}\left(L_{2}, S_{0}\right.$, etc., in Table 3). (3) Rotations are usually not commutative. For example, $x y \neq y x$ or $\mathrm{L}_{1} \neq \mathrm{F}_{0}$ (Table 2 ).

Both Type I and II are simple rotations about one axis, and the only difference is $90^{\circ}$. They may be grouped into one level of difficulty of visualization. When designing tests for spatial visualization, it would be preferable to cover all 24 views (including the initial view). If more or less views are to be used in an assessment, the degree of difficulty of visualization should be taken into consideration. Depending on the goal of assessment, questions may be chosen from appropriate levels of difficulty of visualization as listed in Table 4. For example, if a test intends to assess all levels of visualization, an equal number of question items may be chosen from each type of rotations as listed in Table 4. A spatial visualization test should provide a true assessment of students' visualization skills and reflect the fact that the more complicated the rotation, the harder the visualization.

\section{Discussion of Sample Visualization Tests}

From the possible orthogonal rotations as listed in Table 4, a well designed visualization test, especially a standardized test, should have (a) a fair representation of the 24 possible views of orthogonal rotations, and (b) an even distribution of the types of the orthogonal rotations. When test problems are randomly selected from a test bank, the above guidelines should also be taken into consideration.

Two visualization tests of orthogonal rotations, which have been widely used by engineering and technology majors, are analyzed here using the above findings and criteria. The two tests are the Purdue Spatial Visualization Test - Visualization of Rotations (PSVT-R) developed by Guay ${ }^{7}$, and Sorby's ${ }^{4}$ workbook on spatial visualization.

\subsection{The PSVT-R test}

The PSVT-R test is a widely used test that contains 30 multiple-choice problems of orthogonal rotations. The students are to select a rotated view that matches the rotations of a given object. The problems are sorted according to the degree of difficulty of visualization and listed in Table 5 (Refer to Figure 2 and Table 4 for the views and type of rotations). 
Table 5. Views in the PSVT-R test

\begin{tabular}{|c|c|c|c|c|c|c|c|c|c|c|c|c|c|c|c|c|c|c|c|c|c|c|c|}
\hline Type of Rotations & \multicolumn{6}{|c|}{ I } & \multicolumn{3}{|c|}{ II } & \multicolumn{8}{|c|}{ III } & \multicolumn{6}{|c|}{ IV } \\
\hline Views & $\mathrm{F}_{3}$ & $\mathrm{~L}_{0}$ & $\mathrm{R}_{3}$ & $\mathrm{~S}_{2}$ & $\mathrm{~T}_{1}$ & $\mathrm{~T}_{3}$ & $\mathrm{~B}_{0}$ & $\mathrm{~B}_{2}$ & $\mathrm{~T}_{2}$ & $\mathrm{~F}_{0}$ & $\mathrm{~F}_{2}$ & $\mathrm{~L}_{1}$ & $\mathrm{~L}_{3}$ & $\mathrm{R}_{0}$ & $\mathrm{R}_{2}$ & $\mathrm{~S}_{1}$ & $\mathrm{~S}_{3}$ & $\mathrm{~B}_{1}$ & $\mathrm{~B}_{3}$ & $F_{1}$ & $\mathrm{~L}_{2}$ & $\mathrm{R}_{1}$ & $\mathrm{~S}_{0}$ \\
\hline Number of Views & 2 & 2 & 0 & 1 & 1 & 0 & 2 & 3 & 3 & 0 & 1 & 0 & 2 & 1 & 0 & 2 & 2 & 0 & 2 & 0 & 2 & 3 & 1 \\
\hline Total & \multicolumn{6}{|c|}{6} & \multicolumn{3}{|c|}{8} & \multicolumn{8}{|c|}{0} & \multicolumn{6}{|c|}{8} \\
\hline
\end{tabular}

Note: The initial view $\mathrm{T}_{0}$ is not listed. Only one of the simplest rotations is listed for each view.

As listed in Table 5, 7 of the 23 rotated views are not represented in the PSVT-R test. Several views are repeated up to 3 times. There are 8 views of Type II rotation, which has far more views than its base number of 3 views (Table 4). A previous comparison of the PSVT-R test results against the degree of difficulty of visualization showed that, in two thirds of the mean score differences between the pairs of the types of rotations, the test performance of students was not significantly lowered when the difficulty increased ${ }^{8}$. The fact that nearly one third of the rotated views were not represented in the PSVT-R test and there was an uneven distribution of the rotated views may explain why the test performance was not significantly lowered when the difficulty of visualization increased.

\subsection{Sorby's test}

Sorby ${ }^{4}$ developed a workbook on 3D spatial visualization based on earlier work by Baartmans and Sorby ${ }^{10}$. The workbook contains various types of spatial visualization test problems, including a total of 135 orthogonal rotations (A software package is also supplied with the workbook that provides 48 additional exercises on orthogonal rotations, but it is not included in this analysis). In addition to the traditional questions of multiple choices of rotated views, there are also multiple choices and analytical solutions (figuring out) of degree, direction, and sequence of rotations. The workbook also provides test problems that require students to sketch the isometric views after specified orthogonal rotations. All of the objects are isometric drawings, which may be viewed as built up by cubes with seamless connections. The coordinate axes and isometric grids are provided for all of the orthogonal rotation problems. The coordinate axes help spatial visualization ${ }^{9}$. The isometric grids, which match the cubes, may help to visualize the dimensions and features of the objects. The test problems are sorted in Table 6 (Refer to Figure 2 and Table 4 for the views and type of rotations).

Table 6. Views in Sorby's test

\begin{tabular}{|c|c|c|c|c|c|c|c|c|c|c|c|c|c|c|c|c|c|c|c|c|c|c|c|}
\hline Type of Rotations & \multicolumn{6}{|c|}{ I } & \multicolumn{3}{|c|}{ II } & \multicolumn{8}{|c|}{ III } & \multicolumn{6}{|c|}{ IV } \\
\hline Views & $\mathrm{F}_{3}$ & $\mathrm{~L}_{0}$ & $\mathrm{R}_{3}$ & $\mathrm{~S}_{2}$ & $\mathrm{~T}_{1}$ & $T_{3}$ & $\mathrm{~B}_{0}$ & $\mathrm{~B}_{2}$ & $T_{2}$ & $\mathrm{~F}_{0}$ & $\mathrm{~F}_{2}$ & $\mathrm{~L}_{1}$ & $\mathrm{~L}_{3}$ & $\mathrm{R}_{0}$ & $\mathrm{R}_{2}$ & $\mathrm{~S}_{1}$ & $\mathrm{~S}_{3}$ & $\mathrm{~B}_{1}$ & $\mathrm{~B}_{3}$ & $\mathrm{~F}_{1}$ & $\mathrm{~L}_{2}$ & $\mathrm{R}_{1}$ & $\mathrm{~S}_{0}$ \\
\hline Number of Views & 5 & 4 & 10 & 11 & 6 & 9 & 8 & 9 & 10 & 19 & 5 & 4 & 4 & 5 & 7 & 11 & 7 & 1 & 0 & 0 & 0 & 0 & 0 \\
\hline Total & \multicolumn{6}{|c|}{45} & \multicolumn{3}{|c|}{27} & \multicolumn{8}{|c|}{62} & \\
\hline
\end{tabular}

Note: The initial view $\mathrm{T}_{0}$ is not listed. Only one of the simplest rotations is listed for each view. 
As Table 6 shows, there is only one view of Type IV rotations among the total of 135 rotational views. The distribution of the views is fair in Type II rotations, but there is a large span of the distribution of the views in Type I and Type III rotations, ranging from 4 to 11 and 4 to 19 respectively.

\section{Discussion}

In testing visualization by rotation, inclined, oblique, and curved surfaces are harder to visualize in some cases. The objects used in the mental rotation tests developed by Shepard and Metzler ${ }^{5}$ and Vandenberg and Kuse ${ }^{6}$ were face-to-face connected cubes; therefore, they were simple normal surfaces. All of the objects presented in Sorby's ${ }^{4}$ workbook problems also contained only normal surfaces (some other surfaces were included in the software exercises.) The PSVT$\mathrm{R}$ test developed by Guay ${ }^{7}$ was unique in that it contained all types of surfaces, although primarily inclined surfaces. For the 30 objects used in the PSVT-R test, 23 objects contained inclined surfaces, 3 oblique, 5 curved (cylindrical), and only 2 normal surfaces only (because some objects contained combined types of surfaces, the sum of these objects is more than 30 ). Because all types of surfaces exist in many real world products, it may be a good idea to include them in visualization tests. One must be careful not to include full axial symmetric objects in order to avoid ambiguous answers.

Since there are an unlimited number of orthogonal rotations to generate the same view, the simplest rotations to generate a view are usually preferable in designing a test. Students should be allowed to use the shortest or easiest way to visualize an object. Unless it is for the purpose of practice, test questions that are open-ended with unlimited answers should be avoided.

A computerized test bank is preferable for spatial visualization tests so that the pretest/posttest effects and other memorizations may be reduced or eliminated. A random selection of test questions from a large pool of each type of rotations will not only provide the flexibility of the number of problems in each test, but also guarantee the fair presentation and even distribution of the rotational views and types of orthogonal rotations.

\section{Conclusion}

Orthogonal rotations are $90^{\circ}$ and its multiple rotations of a 3D object about the axes of the Cartesian coordinate system. This paper proves that there are totally 24 axonometric views of an object at a projection angle. As a special case, there are only a total of 24 isometric views of an object. There are an unlimited number of orthogonal rotations that result in the same view. This paper presents one set of simplest rotations in four types, based on the degree of rotations and the axes involved, for all of the 24 views. The four types of rotations represent different degrees of difficulty of spatial visualization. In order to better measure the abilities and skills of spatial visualization, a fair representation of the 24 possible views of orthogonal rotations and an even distribution of the four types of rotations should be considered when designing the tests. 


\section{Acknowledgements}

The author would like to thank NASA Administrator's Fellowship Program (NAFP) and NASA Langley Research Center for providing him the opportunity to write this paper. Currently, the author is a NASA Administrator's Fellow at NASA Langley Research Center in Hampton, Virginia. He is on a one-year leave from Essex County College in Newark, New Jersey. NAFP is sponsored by NASA and managed by the United Negro College Fund Special Programs Corporation. However, the author is solely responsible for the content of this paper.

\section{Bibliography}

1. Miller, C. L. A Historical Review of Applied and Theoretical Spatial Visualization Publications in Engineering Graphics. Engineering Design Graphics Journal, 1996, 60(3), 12-33.

2. Miller, C. L. \& Bertoline, G. R. Spatial Visualization Research and Theories: Their Importance in the Development of an Engineering and Technical Design Graphics Curriculum Model. Engineering Design Graphics Journal, 1991, 55(3), 5-14.

3. Ekstrom, R. B., et al. Kit of Factor-Referenced Cognitive Tests. ETS, Princeton, NJ, 1976.

4. Sorby, S. A. Introduction to 3D Spatial Visualization: An Active Approach. Software by Anne F. Wysocki. 2003 by Delmar Learning.

5. Shepard, R. N. \& Metzler, J. Mental Rotation of Three-Dimensional Objects. Science, Feb. 19, 1971, 171(3972), 701-703.

6. Vandenberg, S. G. \& Kuse, A. R. Mental Rotations: A Group Test of Three-Dimensional Spatial Visualization. Perceptual and Motor Skills, 1978, 47, 599-604.

7. Guay, R. B., Purdue Spatial Visualization Test - Visualization of Rotations, West Lafayette: Purdue Research Foundation, 1977.

8. Yue, J. Spatial Visualization and Graphics Learning. Proceedings of the $4^{\text {th }}$ International Conference on Engineering Design and Automation, July 30-August 2, 2000, Orlando, Florida, 56-61.

9. Branoff, T. J. The Effects of Adding Coordinate Axes to a Mental Rotations Task in Measuring Spatial Visualization Ability in Introductory Undergraduate Technical Graphics Courses. Engineering Design Graphics Journal, 1998, 62(2), 16-34.

10. Baartmans, B. G. \& Sorby, S. A. Introduction to 3-D Spatial Visualization. 1996 by Prentice Hall.

\section{JIANPING YUE}

Jianping Yue is an Associate Professor in the Department of Engineering Technologies and Computer Sciences at Essex County College in Newark, New Jersey. Currently, he is a NASA Administrator's Fellow at NASA Langley Research Center in Hampton, Virginia. Dr. Yue received his B.S. and M.S. degrees in Hydraulic and Coastal Engineering from Wuhan University, China, in 1977 and 1982, and a Ph.D. degree in Civil Engineering from the University of Memphis, Memphis, Tennessee in 1990. 